
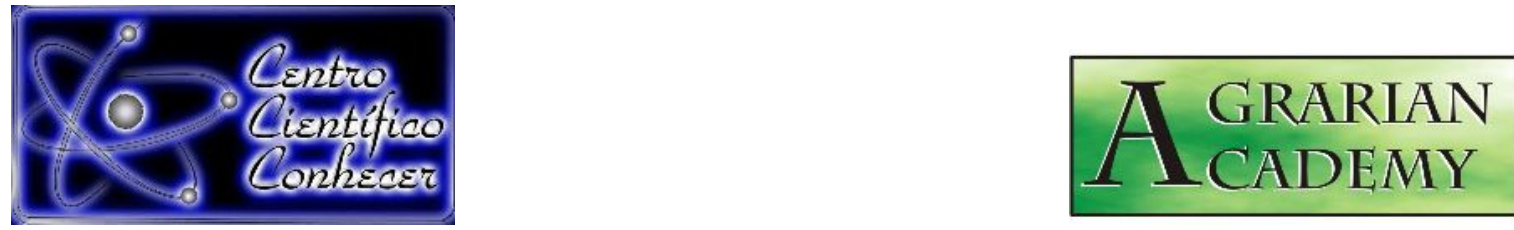

\title{
FEIJÃO-NHEMBA - UMA ANÁLISE DE PREÇOS E COMERCIALIZAÇÃO NA PROVÍNCIA DE SOFALA EM MOÇAMBIQUE
}

\author{
Igor Leonardo Vespucci ${ }^{1}$, Alex Orlando Ndava ${ }^{2}$, Valquíria Duarte Vieira Rodrigues ${ }^{2}$, \\ Érica Basílio Tavares ${ }^{2}$, Cleyzer Adrian da Cunha ${ }^{3}$ \\ ${ }^{1}$ Doutorando em Agronegócio - Universidade Federal de Goiás \\ (igorvespucci@agronomo.eng.br) \\ ${ }^{2}$ Mestrandos em Agronegócio - Universidade Federal de Goiás \\ ${ }^{3}$ Doutor em Economia Aplicada - Universidade Federal de Goiás
}

Recebido em: 19/11/2018 - Aprovado em: 14/12/2018 - Publicado em: 25/12/2018

DOI: 10.18677/Agrarian_Academy_2018B19

\begin{abstract}
RESUMO
O feijão-nhemba constitui a base alimentar de muitas populações rurais moçambicanas devido ao seu elevado valor nutritivo tendo valor expressivo economicamente na agricultura deste país. O objetivo desta pesquisa foi demonstrar as variações de preços desta leguminosa, e analisar as margens de comercialização nos níveis de produtor, grossista (atacado) e retalhista (varejo) na Província de Sofala em Moçambique nos últimos três anos. Para a realização da pesquisa recorreu-se a dados secundários dos preços e taxas de câmbio do Informativo Semanal de Mercados Agrícolas de Moçambique. Conclui-se que os preços do feijão-nhemba na Província de Sofala em Moçambique apresenta grandes variações. A participação do produtor é muito maior em todo o período, com tendência de diminuição. Nos dois primeiros anos, o mercado grossista é o que tem menor participação no preço final pago pelo consumidor, o que não se verifica no último ano, onde tem-se o mercado retalhista com menor participação.
\end{abstract}

PALAVRAS-CHAVE: Economia Rural; Margens; Vigna unguiculata.

\section{BEANS-NHEMBA - AN ANALYSIS OF PRICES AND MARKETING IN SOFALA PROVINCE IN MOZAMBIQUE}

\footnotetext{
ABSTRACT

Beans are the food base of many Mozambican rural populations because of their high nutritional value and have significant economic value in the agriculture of this country. The objective of this research was to demonstrate the price variations of this legume, and to analyze the margins of commercialization at the producer, wholesale (wholesale) and retail (retail) levels in Sofala Province in Mozambique in the last three years. For the accomplishment of the research was used the secondary data of the prices and exchange rates of the Weekly Newsletter of Agricultural Markets of Mozambique. It can be concluded that the prices of beans in Sofala Province in Mozambique vary widely. Producer participation is much larger over the whole AGRARIAN ACADEMY, Centro Científico Conhecer - Goiânia, v.5, n.10; p. 932018
} 
period, with a declining trend. In the first two years, the wholesale market has the lowest share of the final price paid by the consumer, which is not the case in the last year, where we have the retail market with the lowest share.

KEYWORDS: Rural Economy; Margins; Vigna unguiculata.

\section{INTRODUÇÃO}

Moçambique possui uma área total de $799.380 \mathrm{~km}^{2}$ dos quais cerca de 36 milhões de hectares, ou seja, quase a metade do território nacional é de terra arável, na sua maioria inexplorada. Com recursos naturais abundantes, apresenta condições agroclimáticas favoráveis à produção em escala (OPPEWAL; CRUZ, 2017). Nos dizeres dos mesmos autores, a agricultura é a principal atividade econômica de cerca de $70 \%$ da população (no total 28.9 milhões de habitantes em 2017). A produção agrícola é de subsistência, e dominada por pequenos camponeses.

O feijão-nhemba, Vigna unguiculata (L) Walp é original da região central e oeste da África sendo uma das leguminosas melhor adaptadas às regiões secas dos trópicos que cobrem parte da África, Ásia e Américas. É uma planta rústica, de ampla variabilidade genética, com grãos ricos em proteína, minerais e fibras, constituindo-se em componente alimentar básico em regiões áridas e semiáridas (SINGH et al., 2002).

Esta leguminosa é comercializada sob forma de grão. Os principais fatores limitantes para os camponeses são a irregularidade da chuva, baixa fertilidade de solo, baixa qualidade da semente, pouca disponibilidade de meio de produção, fraco sistema de armazenamento, a falta de incentivos para a comercialização e deficiente assistência por parte da rede de extensão local (LINHARES et al., 2018).

O preço é o valor de troca que se oferece por alguma coisa que satisfaça uma dada necessidade ou desejo. Sendo assim, este, é o valor estabelecido e aceito pelo vendedor para efetuar algo. No preço poderá estar ou não incluído, além do custo, o eventual lucro ou prejuízo. Os produtos vendidos podem ser diferentes entre os níveis de mercado resultado das perdas de comercialização, normalmente causadas por vários fatores tais como amassamento e apodrecimento, conforme a perecibilidade do produto (VASCONCELLOS; GARCIA, 2014).

Zanin e Bacch (2016) relatam que a margem de comercialização é a diferença entre o preço pelo qual um intermediário (ou um conjunto deles) vende uma unidade de produto e o pagamento pela compra de quantidade equivalente para vender essa unidade. A equivalência faz-se necessária, para contabilizar perdas nos processos de armazenamento e transporte, além da existência de subprodutos.

Nestes moldes, o objetivo desta pesquisa foi demonstrar as variações de preços desta leguminosa, e analisar as margens de comercialização nos níveis de produto, grossista (atacado) e retalhista (varejo) na Província de Sofala em Moçambique nos últimos três anos. Para a realização da pesquisa recorreu-se aos dados secundários dos preços e taxas de câmbio do Informativo Semanal de Mercados Agrícolas de Moçambique.

\section{MATERIAL E MÉTODOS}

Os dados obtidos relativos aos preços e às taxas de câmbio basearam-se numa amostra de dados secundários do Informativo Semanal de Mercados Agrícolas de Moçambique, Região e Mundo, nas publicações do Sistema de Informação de Mercados Agrícolas do Ministério da Agricultura. Utilizou-se uma 
amostra de 12 pontos (médias trimestrais para três anos) referentes aos períodos de janeiro de 2015 a dezembro de 2017.

Os dados coletados foram: preço real médio mensal do feijão-nhemba em Metical (moeda vigente em Moçambique), por quilo $(\mathrm{kg})$ no nível do produtor, grossista e retalhista, na província de Sofala. Tais dados foram cambiados na sua respectiva data de referência para o dólar, fato que é casual na região (Tabela 1). Os dados foram analisados com o apoio do software EViews, versão 9.

TABELA 1. Valores médios das taxas de câmbio do dólar frente ao Metical entre o período de 2015 a 2017.

\begin{tabular}{cccc}
\hline Trimestre & 2015 & 2016 & 2017 \\
\hline $1^{\circ}$ & 33,12 & 48,17 & 69,69 \\
$2^{\circ}$ & 35,90 & 56,79 & 62,33 \\
$3^{\circ}$ & 39,71 & 72,54 & 61,88 \\
$4^{\circ}$ & 50,07 & 75,56 & 60,76 \\
\hline
\end{tabular}

Os preços foram dispostos em tabelas e gráficos para demonstração e comparação nos três níveis de mercado: produtor, grossista e retalhista. As margens de comercialização correspondem às diferenças de preços de um nível de mercado a outro. Estas foram analisadas sob o aspecto de: margens brutas que é a diferença em valores absolutos dos preços comercializados entre os níveis de mercado; composição das margens, que corresponde ao modo de formação destas margens, no que respeita valores fixos, percentuais ou mistos.

$$
\begin{gathered}
\mathrm{Pp}=\text { preço no âmbito da propriedade rural, preço recebido pelo produtor; } \\
\mathrm{Pg}=\text { preço no âmbito grossista, preço de venda do grossista; } \\
\mathrm{Pr}=\text { preço no âmbito retalhista } \text {, preço pago pelo consumidor. }
\end{gathered}
$$

As fórmulas para composição das margens estão de acordo com a metodologia de Mendes e Padilha Júnior (2007) e estão descritas no quadro 1.

QUADRO 1. Definições das margens da comercialização.

\begin{tabular}{|c|c|c|}
\hline Margens (M) & Valores absolutos & Valores relativos (\%) \\
\hline Margem total (MT) & $\mathrm{Pr}-\mathrm{Pp}$ & {$[(\mathrm{Pr}-\mathrm{Pp}) / \mathrm{Pr}] \times 100$} \\
\hline Margem de grossista (MG) & $\mathrm{Pg}-\mathrm{Pp}$ & {$[(\mathrm{Pg}-\mathrm{Pp}) / \mathrm{Pr}] \times 100$} \\
\hline Margem de retalhista (MR) & $\mathrm{Pr}-\mathrm{Pg}$ & {$[(\mathrm{Pr}-\mathrm{Pg}) / \mathrm{Pr}] \times 100$} \\
\hline Participação do produtor (Pp) & - & $100-\mathrm{Mt}$ \\
\hline
\end{tabular}

Fonte: Mendes e Júnior (2007)

Onde:

$\mathrm{Pp}=$ preço no âmbito da propriedade rural, preço recebido pelo produtor;

$\mathrm{Pg}=$ preço no âmbito grossista, preço de venda do grossista;

$\mathrm{Pr}=$ preço no âmbito retalhista, preço pago pelo consumidor. 


\section{RESULTADOS E DISCUSSÃO}

Os preços do feijão-nhemba na Província de Sofala, em Moçambique demonstraram uma variação forte no período em análise, com maior foco para o nível do produtor. Conforme se pode observar na Figura 1, os três anos em análise, apresenta grandes variações de preços, nos quais se encontram valores entre US\$ $0,32 / \mathrm{kg}$ a US\$ $1,01 / \mathrm{kg}$, representando uma variação de aproximadamente $100 \%$ num mesmo ano. De acordo com a trajetória observada no gráfico, constatou-se que as oscilações de preços ocorrem de forma aleatória, o que corrobora que tais variações advêm do câmbio internacional.

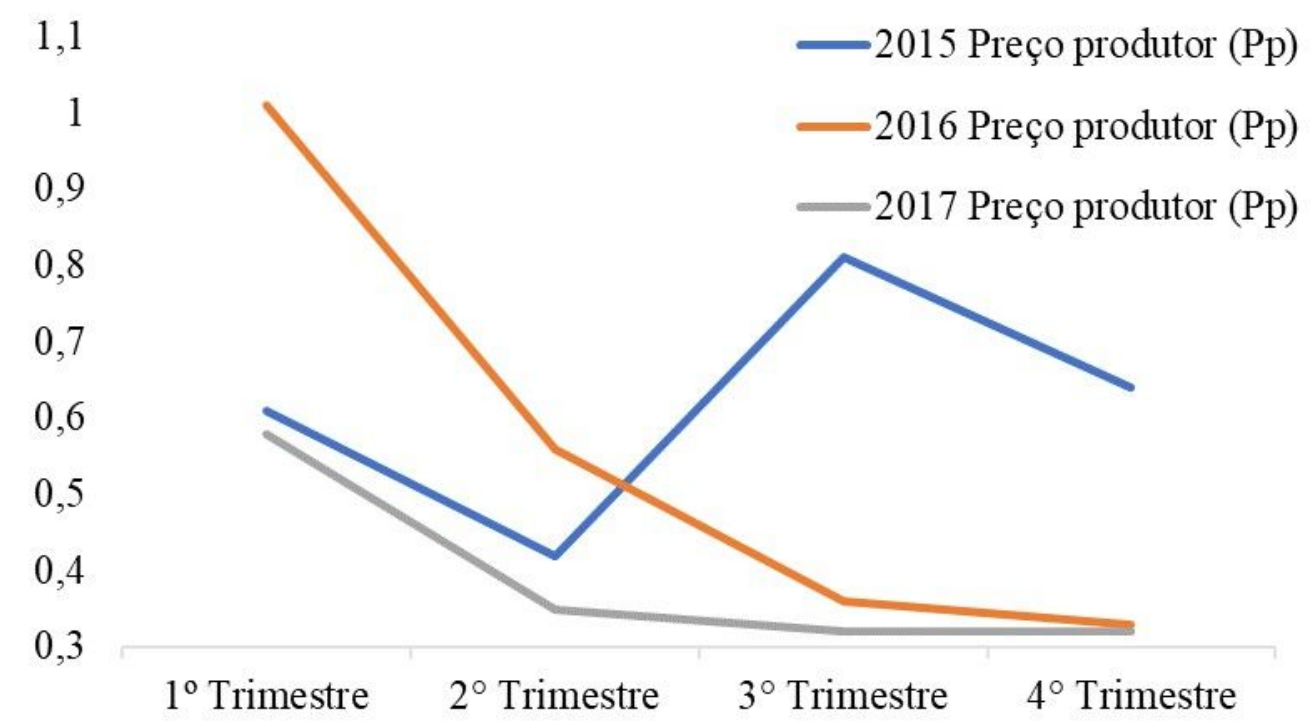

FIGURA 1. Variação de preços trimestrais pagos em dólar ao produtor do feijão-nhemba $(\mathrm{kg})$ na província de Sofala em Moçambique (2015-2017).

Pelas médias anuais (Tabela 2) também pode se verificar que o ano de 2015 apresentou os maiores valores médios. Outro fato relevante é a queda dos preços médios ao nível de produtor, em que o preço médio do ano de 2017 foi o menor no período avaliado. Carneiro e Parré (2005) analisando as transmissões de preços entre produtor, atacado e varejo da cadeia produtiva do feijão no estado do Paraná, Brasil no período de 1995/2003, relataram também que o produtor estabelece seus preços por mark-up (custo a mais sobre o preço final), obtendo o seu lucro a partir do preço a mais que coloca sobre o produto final.

TABELA 2. Média trimestral de preços pagos em dólar ao produtor do feijãonhemba (Kg) na província de Sofala em Moçambique (2015-2017).

\begin{tabular}{cccc}
\hline Trimestre & 2015 & 2016 & 2017 \\
& Preço produtor $(\mathrm{Pp})$ & Preço produtor (Pp) & Preço produtor (Pp) \\
\hline $1^{\circ}$ & 0,61 & 1,01 & 0,58 \\
$2^{\circ}$ & 0,42 & 0,56 & 0,35 \\
$3^{\circ}$ & 0,81 & 0,36 & 0,32 \\
$4^{\circ}$ & 0,64 & 0,33 & 0,32 \\
Médias & 0,62 & 0,57 & 0,39 \\
\hline
\end{tabular}

AGRARIAN ACADEMY, Centro Científico Conhecer - Goiânia, v.5, n.10; p. 962018 
Nos dois primeiros anos analisados, 2015 e 2016, o feijão-nhemba apresentou grandes variações de preços no nível de grossista, ao passo que, no ano seguinte essas variações observadas foram menores, fazendo com que os preços se mantivessem mais estáveis. Verificando a Figura 2, constata-se que 0 ano de 2017 foi o que praticou menores preços neste nível de mercado entre o período avaliado, demonstrando uma tendência decrescente dos preços de feijão-nhemba no nível grossista na província de Sofala em Moçambique. Segundo Barros (1990), os preços no mercado grossista se ajustam instantaneamente e com baixo custo, além das vendas serem centralizadas, de curto prazo, e possuírem maior especialização, com acesso facilitado às informações. Quanto às alterações de preços entre os produtores e o varejo, estas acontecem com certa defasagem, porque os primeiros estão pulverizados e trabalham com pequena quantidade do produto, enquanto o segundo não é especializado.

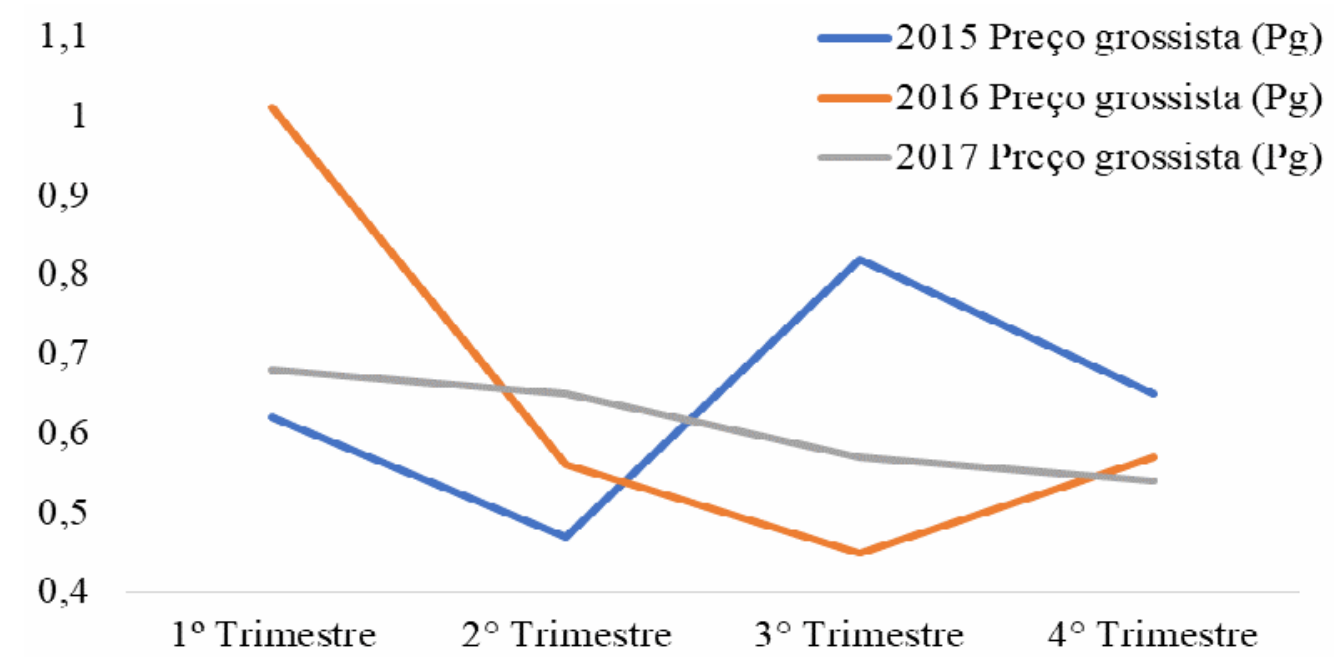

FIGURA 2. Variação de preços trimestrais pagos em dólar ao grossista do feijão-nhemba $(\mathrm{kg})$ na província de Sofala em Moçambique (2015-2017).

$\mathrm{Na}$ Tabela 3 pode-se observar os valores médios encontrados para o quilo (kg) de feijão-nhemba ao nível grossista na província de Sofala em Moçambique (2015-2017). Diferente do nível de produtor, o preço médio do ano de 2016 foi o maior entre os três anos, resultado do agravamento das taxas de câmbio do dólar neste período, o que fez com que aspectos logísticos no nível do grossista agravassem o preço.

TABELA 3. Média trimestral de preços pagos em dólar ao grossista do feijãonhemba (Kg) na província de Sofala em Moçambique (2015-2017).

\begin{tabular}{cccc}
\hline Trimestre & 2015 & 2016 & 2017 \\
& Preço grossista $(\mathrm{Pg})$ & Preço grossista $(\mathrm{Pg})$ & Preço grossista $(\mathrm{Pg})$ \\
\hline $1^{\circ}$ & 0,62 & 1,01 & 0,68 \\
$2^{\circ}$ & 0,47 & 0,56 & 0,65 \\
$3^{\circ}$ & 0,82 & 0,45 & 0,57 \\
$4^{\circ}$ & 0,65 & 0,57 & 0,54 \\
Médias & 0,64 & 0,65 & 0,61 \\
\hline AGRARIAN ACADEMY, Centro Científico Conhecer - Goiânia, v.5, n.10; p. 97 & 2018
\end{tabular}


Os preços ao nível retalhista (Figura 3) também sofreram certas variações no período analisado, as oscilações se inverteram ao final do segundo semestre para alguns anos, assim como aconteceu nos dois níveis de mercado mencionados anteriormente, e também foi o que apresentou maiores valores entre os demais anos, quando o preço do quilo $(\mathrm{kg})$ do feijão-nhemba chegou a custar US $\$ 1,26$ no primeiro trimestre de 2016. Já no ano de 2017 os preços se mostraram inferiores, o quilo da leguminosa apresentou média de apenas US\$ 0,68.

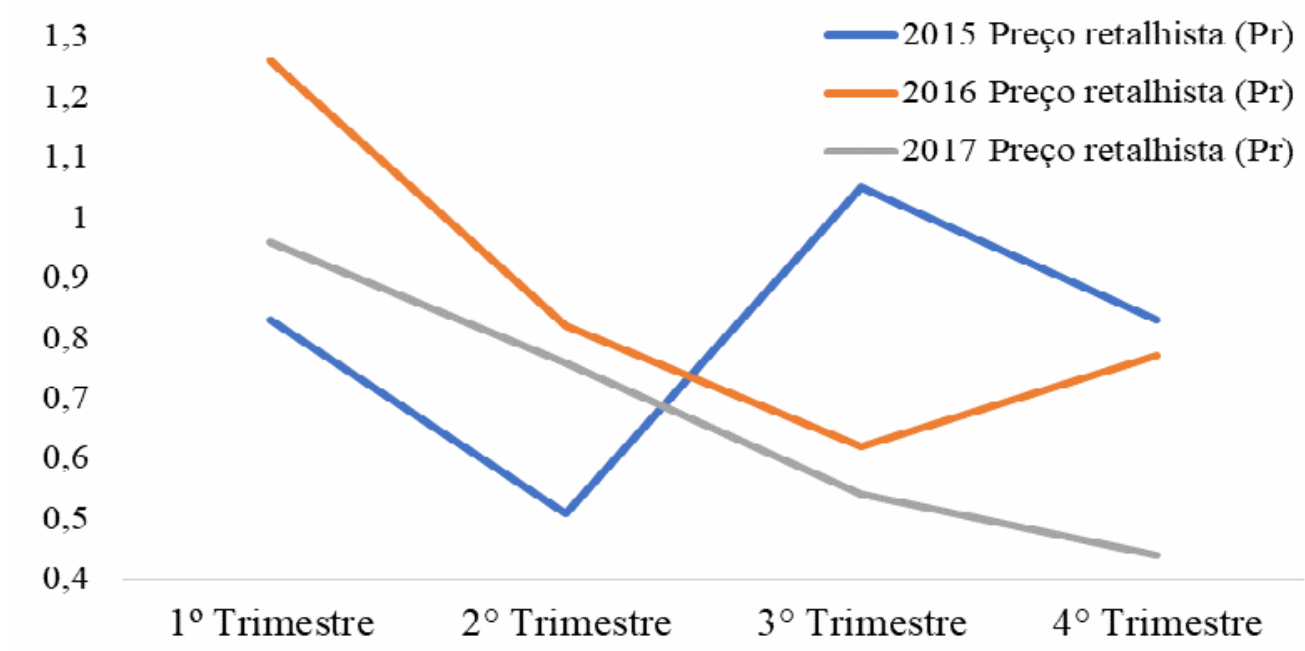

FIGURA 3. Variação de preços trimestrais pagos em dólar ao retalhista do feijão-nhemba $(\mathrm{kg})$ na província de Sofala em Moçambique (2015-2017).

Pelas médias anuais (Tabela 4), verifica-se que no âmbito retalhista a tendência de preços é a mesma dos níveis anteriores, sendo maior no ano de 2016 e menor no ano de 2017. Assim, autor como Sesso Filho (2003) salienta a globalização como fonte que alimenta a concorrência e que leva os supermercados de grande porte a expandirem suas ações, gerando marcas famosas, como as de grandes redes, que estão na maioria dos países desenvolvidos e emergentes. As fusões e associações, combinadas à adoção de tecnologias, ao conhecimento da demanda e à exigência dos consumidores, facilitaram a adoção de estratégias e a liderança de preços deste setor perante os demais atores do processo produtivo.

TABELA 4. Média trimestral de preços pagos em dólar ao grossista do feijãonhemba (Kg) na província de Sofala em Moçambique (2015-2017).

\begin{tabular}{cccc}
\hline Trimestre & 2015 & 2016 & 2017 \\
& Preço retalhista (Pr) & Preço retalhista (Pr) & Preço retalhista (Pr) \\
\hline $1^{\circ}$ & 0,83 & 1,26 & 0,96 \\
$2^{\circ}$ & 0,51 & 0,82 & 0,76 \\
$3^{\circ}$ & 1,05 & 0,62 & 0,54 \\
$4^{\circ}$ & 0,83 & 0,77 & 0,44 \\
Médias & 0,81 & 0,87 & 0,68 \\
\hline
\end{tabular}


Conforme se pode observar nos dados da tabela 5, entre os níveis de mercado seguidos, a margem de comercialização entre o nível de produtor e grossista apresentam uma tendência de crescimento, mas não são expressivas pelo fato de ser menor comparativamente com as outras margens nos primeiros dois anos; já no último ano esta margem demonstrou um aumento expressivo, maior que o dobro comparativamente com os outros anos.

TABELA 5. Diferentes margens de comercialização do feijão-nhemba $(\mathrm{kg})$ na província de Sofala em Moçambique (2015-2017).

\begin{tabular}{lccc}
\hline Período/Margens & $\mathbf{2 0 1 5}$ & $\mathbf{2 0 1 6}$ & $\mathbf{2 0 1 7}$ \\
\hline MG (Margem Grossista) & 0,07 & 0,35 & 0,89 \\
MR (Margem retalhista) & 0,66 & 0,88 & 0,25 \\
MT (Margem total) & 0,73 & 1,22 & 1,15 \\
MTR (Margem total relativa) & $22,24 \%$ & $37,94 \%$ & $40,90 \%$ \\
MGR (Margem grossista relativa) & $3,09 \%$ & $12,02 \%$ & $36,97 \%$ \\
MRR (Margem retalhista relativa) & $19,15 \%$ & $25,91 \%$ & $3,94 \%$ \\
PP (Participação do produtor) & $77,77 \%$ & $62,07 \%$ & $59,11 \%$
\end{tabular}

Entre os níveis de retalhista e grossista (figura 4) essa margem bruta ou absoluta é bem maior, demonstrando crescimento nos primeiros dois anos, seguida de uma diminuição no último ano.

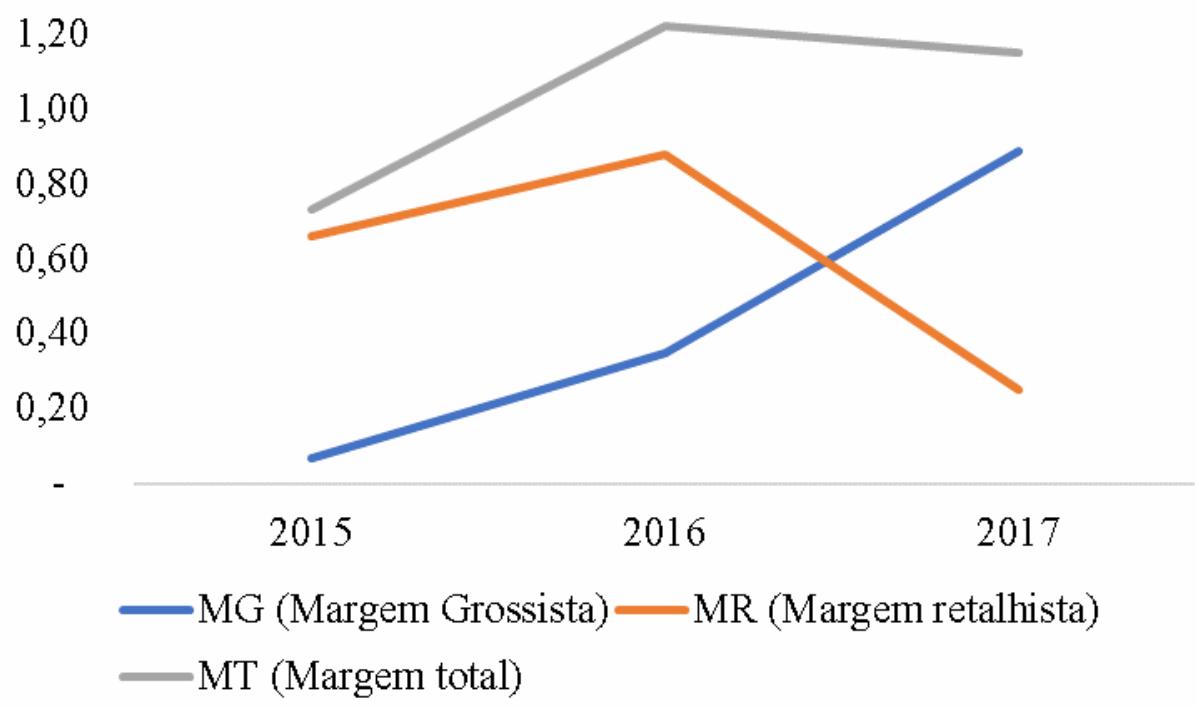

FIGURA 4. Margens absolutas de comercialização do feijãonhemba (kg) na província de Sofala em Moçambique (2015-2017).

Entre os níveis de retalhista e nível do produtor as margens são maiores se comparadas com as duas primeiras margens (grossista e retalhista), com uma tendência de crescimento nos dois primeiros anos e uma ligeira baixa no último ano. Verifica-se com muita facilidade que nas três diferenças de preços, as margens estão aumentando ao longo dos dois primeiros anos em análise, sendo que no 
último ano demonstram uma tendência de baixa, com exceção da Margem do Grossista que continua com a tendência de aumento das margens.

A participação do produtor (Figura 5) é forte no primeiro ano, com tendência de baixa nos dois últimos anos (2016 e 2017). Em termos médios, a margem total de comercialização e a participação do produtor no preço final pago pelo consumidor estão na ordem de $34 \%$ e $66 \%$ respectivamente. Isto significa que para cada USD\$ 1,00 gastos pelo consumidor na compra de feijão-nhemba, USD\$ 3,00 são atribuídos pelos agentes envolvidos no processo de comercialização e USD $\$ 7,00$ pelo produtor.

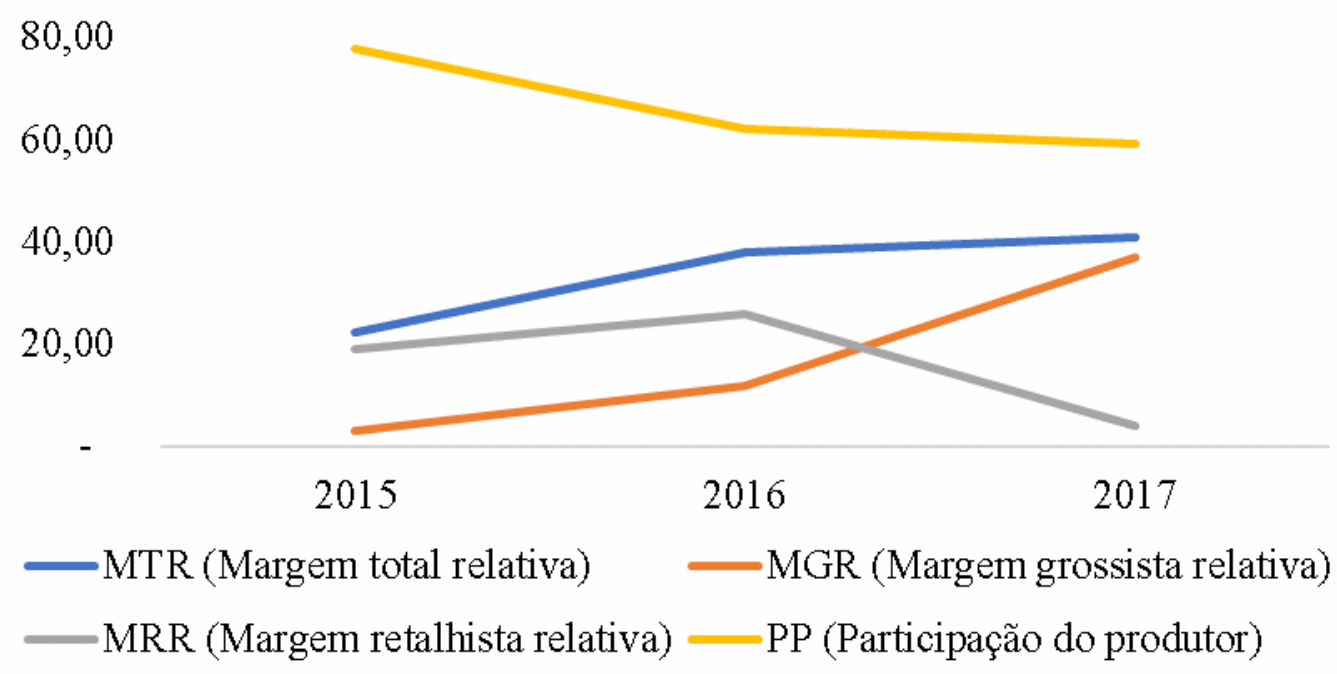

FIGURA 5. Margens relativas e participação do produtor na comercialização do feijão-nhemba $(\mathrm{kg})$ na província de Sofala em Moçambique (2015-2017).

Nos dois primeiros anos a margem retalhista representou maior participação no preço final pago pelo consumidor se comparada com o grossista, o que não se verificou no último ano, em que a margem grossista representou maior participação no preço final pago pelo consumidor.

Um aspecto pertinente a se levar em consideração é a questão de distanciamento das margens de um mercado para o outro, com altas nos dois primeiros anos e baixa no último ano. Os dados demonstram maior ganho do mercado retalhista em comparação com o mercado grossista nos dois primeiros anos, o que não se verificou no último ano onde se tem o mercado grossista a ganhar mais que o retalhista com uma boa diferença de margem.

Outro fato a ser ponderado é que em Moçambique o feijão é produzido principalmente pelos pequenos produtores e são inicialmente adquiridos por intermediários que, quando se aproxima a época da colheita, proliferam nas zonas rurais ao encontro dos produtores, sobretudo das zonas mais remotas, para comprar os seus produtos. Neste patamar, os intermediários como têm maior domínio da informação sobre os preços praticados em outros mercados tendem a manipular os produtores a venderem o seu produto a preços baixos utilizando-se na maior parte das vezes de balanças viciadas (SITOLE; MUDEMA, 2012). 


\section{CONCLUSÕES}

Pode-se concluir que os preços do feijão-nhemba na Província de Sofala em Moçambique apresenta grandes variações de preços. Nos dois primeiros anos a margem retalhista representa maior participação no preço final pago pelo consumidor se comparada com o grossista, o que não se verifica no último ano. A participação do produtor é maior em todo o período, com tendência de baixa.

\section{REFERÊNCIAS}

BARROS, G. S. A. C. Transmissão de Preços pela Central de Abastecimento de São Paulo, Brasil. Revista Brasileira Econômica. Rio de Janeiro, v.44, n.1, p.5-20, jan./mar. 1990.

CARNEIRO, P. T.; PARRÉ, J. L.; A Importância do setor varejista na comercialização de feijão no Paraná. Revista de Economia e Agronegócio, Universidade Federal de Viçosa , v. 3, p. 277-298, 2005.

LINHARES, C. M. S.; FREITAS, F. C. L.; AMBRÓSIO, M. M. Q.; NUNES, G. H. S.; SILVA, K. S. Efeito de coberturas do solo sobre a podridão cinzenta do caule em Vigna unguiculata. Summa Phytopathol., Botucatu, v. 44, n. 2, p. 148-155, 2018. Disponivel: <http://www.scielo.br/pdf/sp/v44n2/0100-5405-sp-44-2-0148.pdf> doi: $10.1590 / 0100-5405 / 174041$

MENDES, J. T. G.; PADILHA JUNIOR, J. B. ; AGRONEGÓCIO: uma abordagem econômica. $1^{1}$ ed. São Paulo: Pearson Prentice Hall, 2007. 367p.

OPPEWAL, J.; CRUZ A. Ministério da Agricultura e Segurança Alimentar . Análise da Cadeia de Valor do Feijão Bóer em Moçambique: Políticas Públicas e Plano de Acção, Disponível em https://www.theigc.org/wpcontent/uploads/2017/12/Relatorio-F.Boer-FINAL2.pdf, 2017, acesso a 19 de Junho de 2018.

SITOLE, ROGÉRIO, F; MUDEMA, JOÃO, A. Análise da flutuação dos preços de alimentos em Moçambique e seu impacto nos consumidores. Rede de Organizações para a Soberania Alimentar (ROSA), 34p, Maputo, 2012.

SESSO FILHO, U. A. O setor supermercadista nos anos 1990. Piracicaba, 2003. 185 p.Tese (doutorado) - Escola Superior de Agricultura "Luiz de Queiroz", Universidade de São Paulo.

SINGH, B.B., J.D.; SHARMA, FREIRE FILHO, F.R. Recente progress in cowpea breeding. In: Fatokun, C.A., Tarawal, S.A., Singh, B.B., J.D.; Kormawa, P.M., Tamo, $M$ (eds). Challengs and opportunities for enchancing sustainable cowpea production. Ibadan: IITA, pp 22-49, 2002.

VASCONCELLOS, M.A.S.; GARCIA, M.E. Fundamentos de economia. $5^{\mathrm{a}}$ ed. São Paulo. Saraiva. 2014. 323p. 
ZANIN, V.; BACCH, M.R.P. Análise da margem de comercialização do arroz gaúcho no mercado de São Paulo, após o Plano Real. Ensaios FEE, Porto Alegre, v.36, n. 4, p. 843-868, mar. 2016. 